\title{
A Systematic Review of the Relationship Between Family Structure and Health Risk Behaviours Amongst Young People: An African Perspective
}

\author{
José Frantz ${ }^{*}, 1$ Zinzi Sixaba ${ }^{2}$ and Mario Smith ${ }^{3}$ \\ ${ }^{I}$ Department of Physiotherapy, University of the Western Cape, Cape Town, South Africa \\ ${ }^{2}$ Faculty of Arts, University of the Western Cape, South Africa \\ ${ }^{3}$ Department of Psychology, University of the Western Cape, South Africa
}

\begin{abstract}
Objective: The aim of this study was to review the published literature on the relationship between family structure and engagement in health risk behaviour amongst youth in African countries.

Methods: A systematic review was conducted between 2000 and 2014. Suitable titles were identified from database searches. Thereafter, abstracts were evaluated along specific inclusion criteria. Eleven full text articles were evaluated for methodological quality using a modified critical appraisal tool and six studies were included in the final review that satisfied the threshold criterion of $70 \%$. A narrative synthesis was completed for all included records to provide a textual answer to the research question.

Results: Findings indicated that there was a relationship between family structure and engagement in health risk behaviour, specifically risky sexual behaviour. The importance of family structure was evident, and the active involvement of parents in the activities of youth is cardinal. The review further underscores that there is lack of methodologically rigorous research that can provide empirical support for and insight into the relationship between family structure and engagement in health risk behaviour.

Discussion: Risky sexual behaviour was the most prevalent outcome assessed across studies. Family structure impacted positively on delaying or reducing engagement in risky sexual behaviour. Diverse family structures were identified and orphans living with caregivers were identified as a particular structure that might be more prevalent in the African context. Parental involvement and investment in adolescent activities were more strongly identified as an important factor. There is a lack of and need for more methodologically rigorous research to gain empirical support for and insight into the relationship between family structure and health risk behaviours.
\end{abstract}

Keywords: Africa, family structure, health risk behaviour, Systematic review, youth.

\section{INTRODUCTION}

The increased engagement in health risk behaviours among youth has been well documented $[1,2]$. Policymakers and researchers have looked more seriously at prevention as a potentially cost-effective approach to reduce the prevalence and sequelae of these behaviours e.g. crime, teenage pregnancies, school drop-out, risky sexual behaviour and substance abuse [3]. Models for prevention of adolescent health-risk behaviours focused on the risk and protective factors predictive of these behaviours in an attempt to understand the aetiology of engagement in health risk behaviours amongst youth $[4,5]$. Research indicates that many of the same factors predict these different outcomes including, but not limited to family structure and function [6, 7]. Engagement in health-risk behavior by adolescents takes place within the sociocultural context of families and their neighborhoods as they are socialised or shaped in part by the

*Address correspondence to this author at Faculty of Community and Health Sciences, University of the Western Cape, Private Bag, x17, Bellville 7530, South Africa; Tel: 27219592163; Fax: 27219592755;

E-mail: jfrantz@uwc.ac.za values and beliefs of their parents and society [8]. Childhood family environments represent vital links for understanding mental and physical health across the life span [9].

Literature has evaluated the impact of family on adolescent behavior in different ways. Studies explored parental involvement $[10,11]$, parental communication [12] parental monitoring [13], family processes [14], family health and dysfunction [15] family function [16] family interventions [17] and family structure [18]. For the purposes of this article the focus will be on family structure and the authors recognise that family structure is not static [19]. Family structure is an important aspect of the family context that has been linked with many child development outcomes. In order to understand family structure, we realise that it may change over the lifespan of a child and may vary from, two parents at home to one parent of either sex or to a relative. More importantly, it is necessary to understand that family structure in the African context and globally have changed over the years for various reasons such as economic conditions, education and disease $[20,21]$. With the increase in women joining the labour force in Africa, single femaleheaded households have become a popular phenomenon [22]. In addition, this phenomenon has also led to an increase 
in grandparents rearing their grandchildren to allow mothers to be breadwinners [23-25]. For example, multi-generational co-residence has been a culturally entrenched norm historically for nine-tenths of South African society [26, 27] and co-residence with family remains a norm and a widely preferred option for the majority of the South African population [28-30]. Thus the concept of multi-generational households is increased and reinforced. Literature highlights that the extended family ethos in Africa thus remains intact $[31,32]$. All of this has been compounded by the effects of HIV/AIDS that has affected entire family units consisting of women, children and the extended family [29]. HIV/AIDS has contributed to the change of family structures and function with the main consequence of HIV/AIDS yielding an increase in the number of orphans and thus child-headed homes [30]. These families often live below the family threshold and the well-being of these families is thus threatened [33-35].

As this shift of family structure is occurring, it is presumed that family processes and the well-being of children will be influenced. Research on the relationship between family structure and health risk behaviours by children is evident, but has produced inconsistent results. Recent research has shown that bonding to school and family protects against a broad range of health-risk behaviours in adolescence [7]. Characteristics of the family and household such as parents' type of marriage, family structure, family stability, and living away from home are also important factors associated with adolescent behaviors [36, 37]. In general, research on family structure and adolescent wellbeing has indicated that children in homes with married couples have a better well-being than those in single parent homes or cohabitating homes [31, 32, 34]. Studies have also reported that adolescents from nuclear families are less likely to engage in risky behaviours such as drinking [33] or smoking [34]. Factors such as divorce have also been reported to be related to risky adolescent sexual behaviour [35]. In addition, it was found that single parent homes tend to have fewer financial resources and thus the socioeconomic status of the family may contribute to various aspects of the life of adolescents [36]. It is thus evident that the role of family structure has been highlighted as being vital in helping youth be resilient to most risk factors associated with adolescent substance use, violent behavior and sexual behavior and for promoting healthy adolescent behaviors [37].

There has been evidence specifically that family function and family structure are predictors of participation in risky behavior such as adolescent sexual initiation and alcohol uses include [38, 39]. Adolescents who perceive their relationships with their parents to be poor are reportedly more pessimistic, have lower self-esteem, and have more depressive symptoms than adolescents who have good relationships with their parents thus predisposing the former to engaging in risky behavior [40, 41]. Literature has indicated that family processes fully accounted for the higher levels of delinquency exhibited by adolescents from singlefather versus single-mother families [41]. It has been reported that dysfunctional families had significantly more sexually active respondents [17]. We note that dysfunctional families are not necessarily linked to family structure, but to the family processes where roles and responsibilities become unclear and thwarted. Research has demonstrated that parental involvement affects adolescent behavior and this can be positively influenced through careful monitoring of children on the part of parents [41]. This is a demanding role and in single parent homes and extended family homes, it becomes difficult to decide whose responsibility the monitoring becomes. Children of disrupted families are thus at a higher risk of initiating the use of controlled substances and engaging in sexual intercourse [42]. A firmer understanding of the mechanisms that underlies the association between family structure and engagement in health risk behaviour among youth is needed in order to design effective intervention strategies.

Functioning of children and families is dependent on both internal and external factors [43]. In Africa and some other countries, families living in poverty and crime-ridden societies are at increased risk, as unhealthy behaviors are more likely to emerge with a specific challenge for youth. There have been reports that as the family structure disintegrates and more single parent homes emerge, there are associated challenges. It has been postulated that children raised in female-headed homes are more likely to live in poverty than those from married-couple homes [44]. Having said this, literature acknowledges that family structures are increasingly becoming more diverse and complex (i.e. divorce, remarriage, single-parent household, common- law relationship) [44]. The lack of contextual findings specific to African countries may result in an underestimation of the effect of family structure on the promotion of positive health behaviors amongst youth. Authors have cautioned that statistically significant findings often came from models that did not adequately control for other measures of family connectedness resulting in -reliance on overly unsophisticated empirical techniques to control for confounders [15]. Thus, there is a need for two processes in future research a) more intentional attempts at sophisticated modeling and hypothesis testing and b) a more systematic evaluation of primary studies reporting on the impact of family structure on adolescent behavior e.g. engagement in health risk behaviors whilst acknowledging that family means different things to different people. Families may span several generations, several households; and may change in response to life events such as divorce, remarriage, and children leaving the parental home, especially in African countries. This article reports on a systematic review of quantitative studies reporting on the relationship between family structure and engagement in health risk behaviour among youth from an African perspective between 2000 and 2014.

\section{RESEARCH QUESTION}

The study evaluated published findings related to the relationship between family structure and the engagement of youth in health risk behaviors in Africa. The review question was formulated to specifically identify youth or adolescents in Africa as the target population, and their engagement in health risk behavior as the outcome. The review evaluated family structure in the families of origin as the issue impacting participation or non-participation in health risk behavior.

Theoretical definitions: family structure was defined as the combination of relatives that comprise the adults in the family. In the African context, African family structures 
being practiced in different parts of the continent include (a) nuclear family, (b) extended family, (c) single parental family, (d) step family, (e) matrilineal family structure and (f) patrilineal family structure [45]. Health risk behaviour was defined as any activity undertaken by people with a frequency or intensity that increases risk of disease or injury [46] and included behaviours such as, substance abuse, sexual activity, physical inactivity, alcohol use, or smoking. For the purposes of this study, youth or adolescence was not defined as the researchers wanted to determine if there are differences in the age ranges provided in respective studies for adolescence. Furthermore a delineation of an age range from the researchers could adversely impact the eligibility of studies where youth is delineated differently due to cultural considerations.

\section{MATERIALS AND METHODOLOGY}

This study was a systematic review that evaluated published studies on the relationship between family structure and engagement in health risk behaviour among youth in African countries. The inclusion criteria for this review were publications between 2000 and 2014, and were written in or translated into English. This period was chosen as a previous review [44] cited literature from 1999 that indicated that there had been transformation in the African family. Thus the period as from 2000 was considered relevant as changes in family structures were reportedly due to a response to social, economic and political changes. The review was limited geographically to the African continent as the researchers believed that there may be intercontinental differences in engagement in risk behaviours. Similarly family structure was thought to differ in African countries given the more collectivist approach to family life and culture [44]. Eligible studies had to use quantitative methods to examine and report on the relationship/ association between family structure and engagement of youth in health risk behaviour.

\section{Search Strategy}

A search was conducted between June and July 2014 using databases and journals from Science Direct, Ebscohost (Psychinfo, Medline, Academic Search Complete), BioMed Central, PubMed, Directory of Open Access Journal (DOAJ) and SAGE Journals. Search terms included family structure (single parent, single father, etc), health risk behaviours, youth and adolescent. Subject headings and MeSH terms included "parents", "family," "family structure (single parents, extended family, nuclear family)" "family context" "parent -child relations" and "health risk behavior $v s$ health risk behavior" From the results that the searches yielded, the titles and abstracts were reviewed and examined using the inclusion criteria as described above. In order to determine study eligibility, two reviewers (JF and ZS) independently conducted the data base search for suitable titles and reviewed abstracts for eligibility. Full text articles were retrieved and two reviewers independently assessed the articles to determine whether the article adequately met the criteria for inclusion in the review.

\section{Methods of the Review}

One of the researchers (JM) conducted an initial search to determine if there was evidence for this area using the identified key terms. Once this was determined a search of various data bases indicated was conducted by the second author (ZS) and the titles and abstracts was reviewed for eligibility using the PIO (population, issue and outcome) as a guide as mentioned before. Full text articles were retrieved from the identified databases and where necessary obtained via inter-library loans in order to evaluate the methodological quality using a critical appraisal tool.

\section{Methodological Quality Appraisal}

The methodological quality for the studies was assessed using an instrument (Table 1) adapted from previous systematic reviews that focussed on reviewing prevalence studies [47-49]. The tool was adapted because it only focused on one variable whereas we included the assessment of another variable for this review. Thus the variables assessed included family structure and health risk behaviour.

As presented in Table 2, the methodological tool focused on the method of sampling. Studies were classified as bad $(<33 \%)$, satisfactory $(34-66 \%)$ or good $(67-100 \%)$ based on the total score they obtained. Threshold scores for inclusion were set at $70 \%$ i.e. articles with a score greater than $5 / 7$ (71\%) was included in the review.

Search Results: The initial search that was conducted for the review yielded 2366 hits using the keywords family structure and adolescent health risk behaviour. The searches using filters and combinations of terms then yielded 556 hits. Following these searches, the titles and abstracts were reviewed for eligibility and a sample of 130 articles were retrieved by consensus of the reviewers. Eleven articles were evaluated for methodological rigour and quality. Five were excluded based on a poor score according to the methodological quality appraisal tool. The main areas where the articles lacked in methodological rigour and quality were the method of sampling, secondary data and that the relationship between family structure and health risk behaviour was not assessed or reported on. Table $\mathbf{2}$ summarizes the outcome of the methodological appraisal and illustrates that six articles were included in the final review. In addition, Fig. (1) below outlines the process involved in the systematic review and the search results at every step.

\section{Data Extraction}

Two independent reviewers extracted the data using a standard data extraction form. Before the form was finalized for use in this study, it was pilot-tested by the review authors on similar studies not included in this review and minor adjustments were made after discussion. The extracted information was summarised and presented in a tabular form (Table 3) along the following factors: population, risk behaviour measured, effect of family structure on engaging in the risky behaviour. Data was extracted from the narrative information, as well as the figures and tables. 
Table 1. Methodological quality appraisal tool.

\begin{tabular}{|c|c|c|c|}
\hline 1 & \multicolumn{2}{|c|}{$\begin{array}{l}\text { Sampling method: Was it representative of the population intended in the study? } \\
\text { A. Non-probability sampling (including: purposive, quota, convenience and snowball sampling) } \\
\text { B. Probability sampling (including: simple random, systematic, stratified g, cluster, two-stage and multi-stage sampling) }\end{array}$} & 0 \\
\hline 2 & \multicolumn{2}{|c|}{$\begin{array}{l}\text { Was a response rate mentioned within the study? (Respond no if response rate is below 60) } \\
\text { A. No }\end{array}$} & 1 \\
\hline 3 & $\begin{array}{l}\text { Was the measurement } \\
\text { A. No } \\
\text { B. Yes }\end{array}$ & & 1 \\
\hline 4 & \multicolumn{2}{|c|}{$\begin{array}{l}\text { Was it a primary or secondary data source? } \\
\text { A. Primary data source }\end{array}$} & 0 \\
\hline 5 & $\begin{array}{l}\text { Was health risk behavio } \\
\text { A. No } \\
\text { B. Yes }\end{array}$ & & 0 \\
\hline 6 & $\begin{array}{l}\text { Was family structure a } \\
\text { No } \\
\text { Yes }\end{array}$ & & 1 \\
\hline 7 & \multicolumn{2}{|c|}{$\begin{array}{l}\text { Was the relationship/association between family structure and health risk behaviour explored? } \\
\text { A. No }\end{array}$} & 1 \\
\hline \multicolumn{4}{|c|}{ Scoring: Total score divided by total number of items multiplied by 100} \\
\hline \multicolumn{4}{|c|}{ Methodological Appraisal Score } \\
\hline & Bad & Satisfactory & Good \\
\hline & $0-33 \%$ & $34-66 \%$ & $67-100 \%$ \\
\hline
\end{tabular}

Table 2. Methodological appraisal.

\begin{tabular}{|c|c|c|c|c|c|c|c|c|c|}
\hline Author(s) & Q1 & Q2 & Q3 & Q4 & Q5 & Q6 & Q7 & $\%$ & Outcome \\
\hline Negeri (2014) [44] & 1 & 1 & 1 & 1 & 1 & 1 & 1 & $100 \%$ & Include \\
\hline Pilgrim et al. (2013) [45] & 0 & 0 & 1 & 0 & 1 & 1 & 1 & $57 \%$ & Exclude \\
\hline Marchand \& Smolkowski (2013) [46] & 0 & 0 & 1 & 0 & 1 & 0 & 0 & $16 \%$ & Exclude \\
\hline Sidze \& Defo (2013) [47] & 1 & 0 & 1 & 0 & 1 & 1 & 1 & $71 \%$ & Include \\
\hline Ismayilova et al. (2012) [48] & 1 & 1 & 1 & 0 & 1 & 1 & 1 & $85.7 \%$ & Include \\
\hline Defo \& Dimbuene (2012) [49] & 1 & 0 & 1 & 1 & 1 & 1 & 1 & $85.7 \%$ & Include \\
\hline Ntaganira et al. (2012) [56] & 0 & 1 & 1 & 1 & 1 & 0 & 0 & $57 \%$ & Exclude \\
\hline Dimbuene \& Defo (2011) [57] & 1 & 0 & 1 & 0 & 1 & 0 & 0 & $42.8 \%$ & Exclude \\
\hline Camlin \& Snow (2008) [52] & 1 & 0 & 1 & 0 & 1 & 1 & 1 & $71 \%$ & Include \\
\hline Adu-Mireku (2003) [53] & 1 & 0 & 1 & 1 & 0 & 0 & 0 & $42.8 \%$ & Exclude \\
\hline Magnani et al. (2002) [54] & 1 & 0 & 1 & 1 & 1 & 1 & 1 & $85.7 \%$ & Include \\
\hline
\end{tabular}




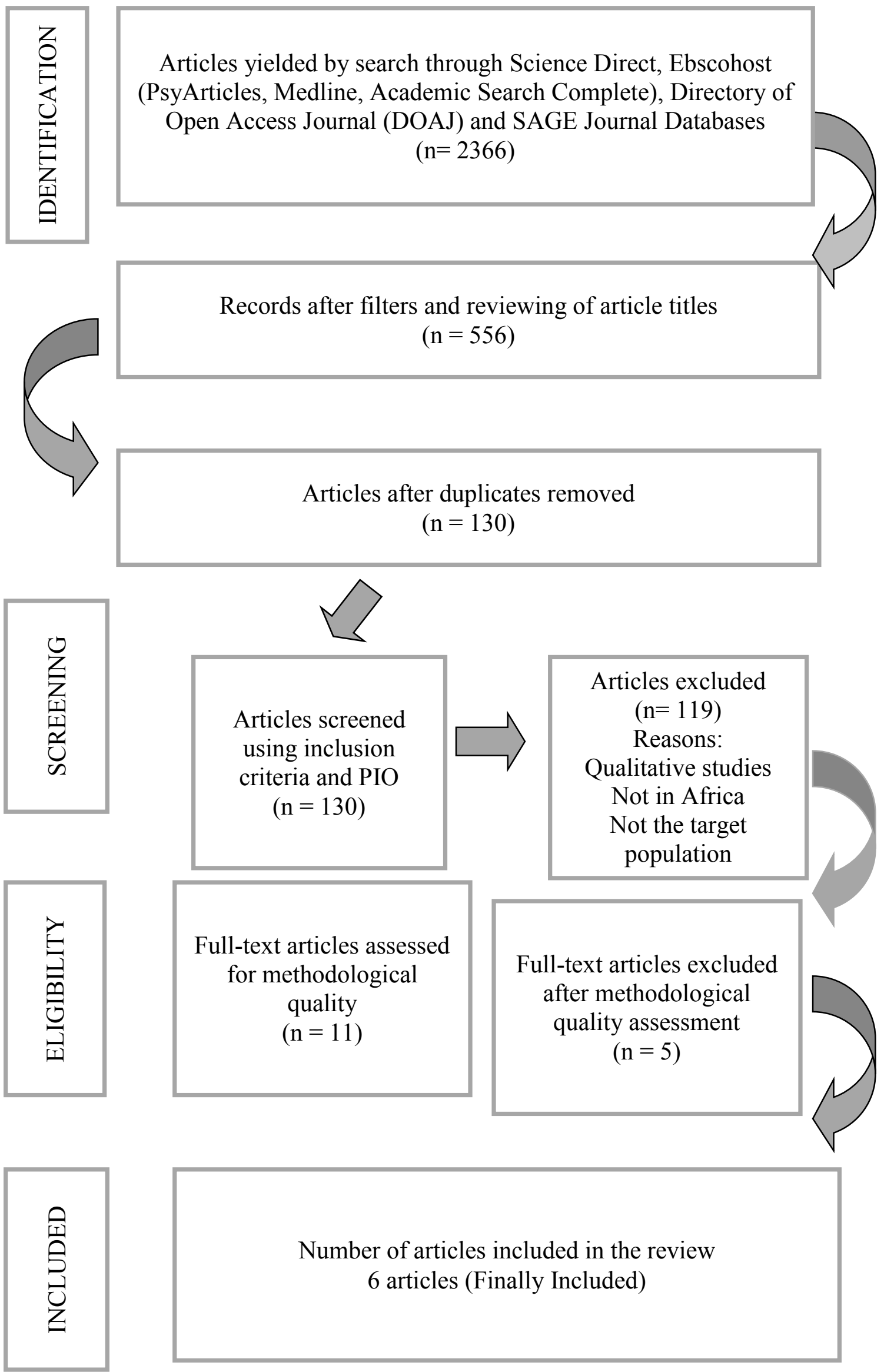

Fig. (1). Flow chart of study screening. 


\section{Data Synthesis}

In this review a narrative synthesis of the findings from the primary studies was completed to deliver a textual answer to the review question. Characteristics of the studies to be included were summarised and presented in a narrative form. The types of family structure was unpacked as well as the behavioural risk factors investigated. In addition, the associations between family structure and engagement in risky behaviour was analysed and presented in a narrative form.

\section{RESULTS}

\section{Description of Studies}

Six articles were included in the final review. The studies were geographically located in Ethiopia [50], Cameroon [51, 55], Zambia [60], South Africa [58] and Uganda [54]. Survey designs were the most frequently used, as well as secondary studies or data analysis obtained from family and health surveys.

The number of participants ranged from 283 participants to 4800 participants and the studies were conducted in setting such as households, primary schools, high schools and communities. The age range of the populations used in the studies ranged from 10 to 24 year old unmarried youth. The target populations for the respective studies included orphans and youth in family groups. Study populations further distinguished between in- and out of school youth.

\section{Family Structure}

In the various studies, family structure differed. In some, family structure was classified under living arrangement and this included living alone, with both parents, a single parent or relatives [50]. In another study, family structure included biological parents, biological mother only, biological father only, other relatives and uncorrelated residents [53]. Other studies included grandparents and other relatives as part of the family structure such as an aunt or uncle [48]. Another article refers to the family structure in terms of one nuclear or two nuclear; or one extended and two extended [55]. It is thus evident that within the African context the definition for family structure varies and researchers in this field should be aware of this diverse definition for family structure. The definition for family structure for this review is supported by the various studies as it includes varied family structures such as a nuclear family, an extended family and a single parent family.

\section{Health Risk Behaviour and Family Structure}

Traditionally, parents have been viewed as having a primary influence on the health risk behaviour of young people [56]. Sexual behaviour was the main health risk behaviour addressed in the respective studies. The association between family structure and engagement in sexual activities was assessed in all the articles. Although living with both parents served as a protective factor against engagement in sexual behaviour, connections with parents did not emerge as strong determinants of adolescent behaviour [60]. This was supported by another study which indicated that if both parents were in the home then youth were more likely to use a condom at first sexual experience [58]. However, there was no relationship between abstinence (no sexual engagement) and family structure. In addition, research highlighted that a caring and supportive family environment could result in a less approving attitude towards sexual risk taking behaviours amongst youth [54, 57]. This was evident in the study with orphans [54] where, the traditional extended African family network provided care for the orphaned adolescents and the supportive environment that encouraged them to make wise choices with regards to sexual behaviours. Thus, the role of the extended family should not be underestimated when considering reports that youth living with both parents were less likely to engage in risky sexual behaviours compared to those living with the biological father only where there is a high risk of having multiple partners [53]. This is supported by another study indicating that youth were less likely to engage in premarital sex when living with parents who monitored their activities and friends compared to those living with one biological parent or with friends [50]. The emphasis should be on the monitoring role rather than the family structure e.g. both or one parent. The extended family can also augment the parental capacity by playing a monitoring role.

\section{DISCUSSION}

The increased engagement in health risk behaviors amongst youth is a worldwide, concern and has served as the impetus for sustained research, particularly prevalence studies [1]. Attempts to intervene in this problem are dependent on an informed understanding of the factors associated with engagement in health risk behaviors. The impacts of these factors are thought to be gendered, racialized and culturally determined. Family structure has been identified as such a factor that needs to be explored from an African perspective to gain systematic and empirical insights into inter-country and continental patterns in the association between family structure and engagement of youth in health risk behaviour [39].

This systematic review aimed to examine the relationship between family structure and the engagement of youth in health risk behaviour in Africa. The results of the current study show that sexual behaviour was the most commonly health risk behavior of concern amongst youth cited in literature. The countries identified in the review included Cameroon, South Africa, Uganda, Zambia and Ethiopia. More studies were expected from South Africa as South Africa has the world's largest HIV-positive population [61].

The review revealed that the definition of youth ranged from 10 to 24 year old unmarried youth that would have implications for the nature and quality of relationships with family relations, care givers or guardians in the home environment. The review also identified that there are different family structures that may vary significantly from traditional western conceptualizations of nuclear family structure as well as blended families. One of the striking observations is the identification of orphans living with caregivers. This is an important finding given the high incidence of HIV-related deaths and HIV- orphans in Africa [62]. 
Table 3. Data extraction from articles.

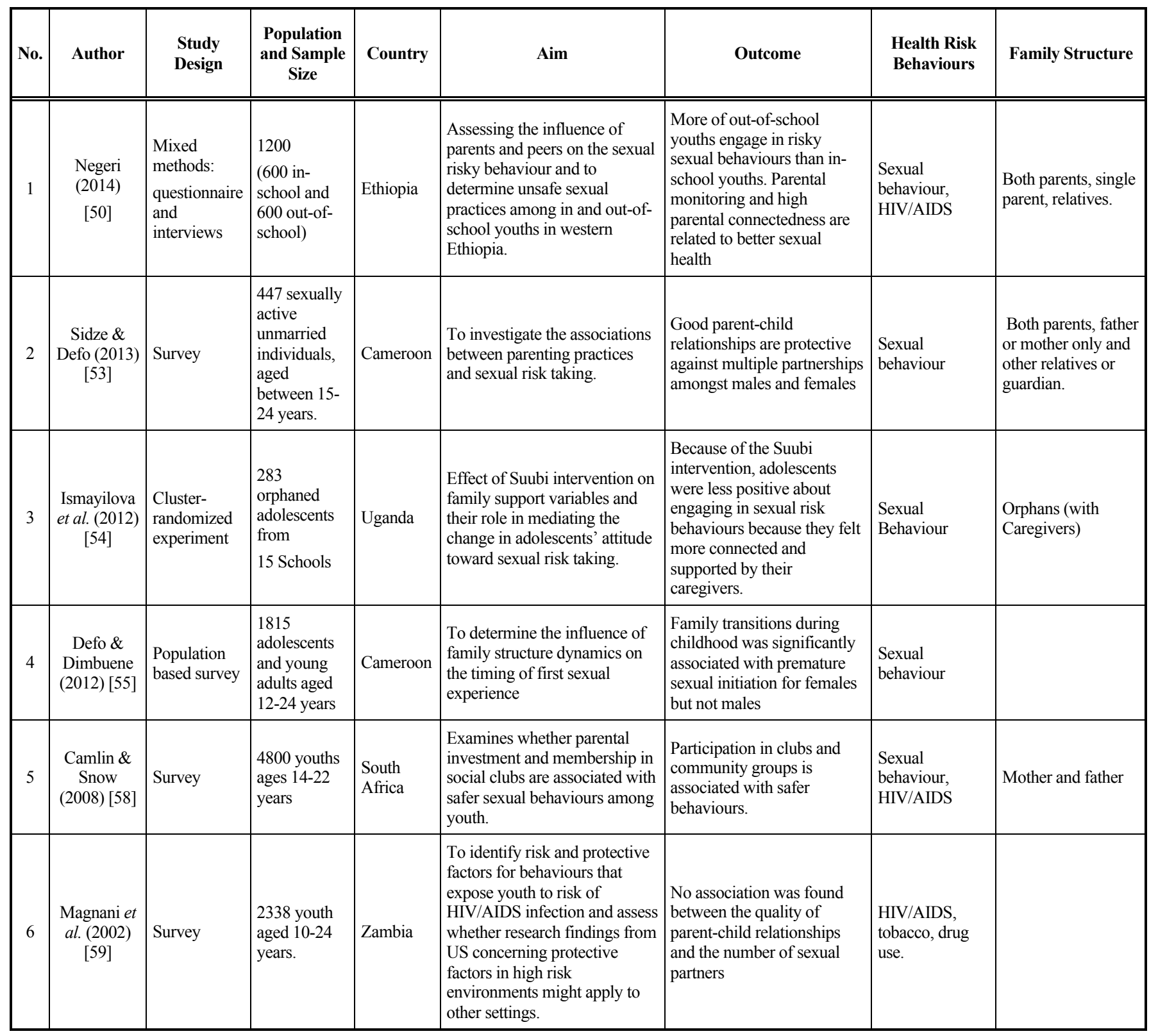

From the review the focus on sexually risky behaviour becomes evident and relates back to the HIV/ AIDS threat in African countries. The lack of methodologically rigorous research into the relationship between family structure and engagement in health risk behaviours was underscored and its impact on successful intervention is concerning. This contributes to the challenge that we have in clearly defining research related to family structure as cautioned in the literature [15].

Findings from the review indicate that there is a relationship or association between family structure and engagement in health risk behavior, specifically sexual activity. Two-parent families were reported to produce positive outcomes such as the delay or reduction of engagement in sexual activity. Similarly, positive attitudes to abstinence were reported in two-parent family structures. The findings underscore the positive influence of parental involvement (especially both parents) and investment, as well as the stability of the family structure on reducing or delaying risky sexual behaviour.

From the review, a clear distinction could not be made between the engagement in sexual behaviour of youth living in one-parent households and those living in two-parent households. In addition, the quality of child-family relationships produced mixed results. One study found that good parent-child relationships (defined as the amount of communication, warmth, love and closeness between mother and child) are protective against multiple partnerships amongst males and females [53] compared to other studies who reported no relationship between parent-child relationships and the number of sexual partners [54]. This finding implies that although family structure is important in reducing the engagement of youth in at-risk behavior, the involvement of parents in the activities of youth and monitoring of these activities are more important. 


\section{CONCLUSION}

The findings of this review confirm that the definition of youth might be more inclusive from an African perspective extending the upper age limit to the twenties that is typically associated with individuation and independence. Similarly, family structures appear to have additional dimensions such as orphans living with guardians or caregivers. The findings support the theorized relationship between family structure and engagement in and attitude towards risky sexual behaviour. The importance of family structure was evident, and the active involvement of parents in the activities of youth is cardinal. The review further underscores that there is a lack of methodologically rigorous research that can provide empirical support for and insight into the relationship between family structure and engagement in health risk behaviour.

\section{LIMITATIONS OF THE STUDY}

This study only considered studies that were published in the English language and that the researchers had access to through the university library websites and interlibrary loans. In this way, the retrieval strategy resulted in a reduced frame of potential studies.

\section{CONFLICT OF INTEREST}

The authors confirm that this article content has no conflict of interest.

\section{ACKNOWLEDGEMENTS}

Declared none.

\section{REFERENCES}

[1] Zulkifli S, Wong Y. Knowledge, attitudes and beliefs related to HIV/AIDS among adolescents in Malaysia. Med J Malaysia 2002; 57(1): 3-23.

[2] Reddy S, James S, Sewpaul R, Koopman F, Funani N. Umthente uhlaba usamila - The South African youth risk behaviour survey, 2008. Cape Town South African Medical Research Council 2010.

[3] Siegel J, Williams L. The relationship between child sexual abuse and female delinquency and crime: A prospective study. J Res Crime Delinq 2003; 40: 71-94.

[4] Hawkins J, Catalano R, Miller J. Risk and protective factors for alcohol and other drug problems in adolescence and early adulthood: implications for substance abuse prevention. Psychol Bull 1992; 112(1): 64-105.

[5] Rosenstock I, Strecher V, Becker M. The health belief model and HIV risk behavior change. Preventing AIDS. Springer: USA 1994; pp. 5-24.

[6] Schor E. The influence of families on child health. Family behaviors and child outcomes. Pediatr Clin N Am 1995; 42(1): 89101.

[7] Resnick M, Bearman P, Blum R, et al. Protecting young people from harm. Findings from the National longitudinal study of adolescent health. J Am Med Ass 1997; 278: 823-32.

[8] Spera C. A review of the relationship among parenting practices, parenting styles, and adolescent school achievement. Educ Psychol Rev 2005; 17(2): 125-46.

[9] Repetti RL, Taylor SE, Seeman TE. Risky families: Family social environments and the mental and physical health of offspring. Psychol Bull 2002; 128: 330-6.

[10] Albrecht C, Teachman JD. Childhood living arrangements and the risk of premarital intercourse. J Fam Issues 2003; 24: 867-94.

[11] $\mathrm{Wu} \mathrm{L}$, Martinson B. Family structure and the risk of a pre-marital birth. Am Soc Rev 1993; 58: 210-32. Parental communication and youth sexual behavior. J Adolescence 2007; 30: 449-66.

Donenberg G, Wilson H, Emerson E, Bryant F. Holding the line with a watchful eye: the impact of perceived parental permissiveness and parental monitoring on risky sexual behavior among adolescents in psychiatric care. AIDS Educ Prev 2002; 14(2): 138-17.

[14) Demuth S, Brown S. Family structure, family processes, and adolescent delinquency: the significance of parental absence versus parental gender. J Res Crime Delinq 2004; 41(1): 58-81.

[15] Goldfarb S, Tarver WL, Sen B. Family structure and risk behaviors: the role of the family meal in assessing likelihood of adolescent risk behaviors. Psych Res Behav Manag 2014, 7: 53-66.

[16] Repetti RL, Taylor SE, Seeman TE. Risky Families: Family Social Environments and the Mental and Physical Health of Offspring. Psychol Bull 2002; 128(2): 330-66.

[17] Muyibi AS, Ajayi I-OO, Irabor AE, Ladipo M. Relationship between adolescents' family function with socio-demographic characteristics and behaviour risk factors in a primary care facility. Afri J Prim Health Care Fam Med 2010; 2(1): 1-6.

[18] Wu LL, Thomson E. Race differences in family experience and early sexual initiation: dynamic models of family structure and family change. J Marriage Fam 2001; 63: 682-96.

[19] Schumm W. Methodological decisions and the evaluation of possible effects of different family structures on children: The new family structures survey (NFSS). Soc Sci Res 2012; 41: 1357-66.

[20] Livingston, Gretchen. "At Grandmother's House We Stay". Washington, D.C.: Pew Research Center Social and Demographic Trends Project, September 2013.

[21] Lofquist DA. "Multigenerational Households: 2009-2011." Washington, D.C.: US Census Bureau, October. American Community Survey brief 2012. ACSBR/11-03.

[22] Antonie P, Nanitelamio J. More single women in African cities. Population 1991; 3: 146-65.

23] McGarry K, Schoeni RF. Social security, economic growth, and the rise in independence of elderly widows in the $20^{\text {th }}$ century. Demography 2000; 37: 221-36.

[24] Intergenerational Relations Global (ILC global). Global Perspectives on Multigenerational Households and Intergenerational Relations An ILC Global Alliance Report March 2012. Available at: www.ilc-alliance.org

[25] Catell M. Zulu grandmothers socialization of granddaughters. S Afr J Gerontol 1997; 6 (1): 14-6.

[26] Bigombe B, Khadiagala G. Major trends affecting families in SubSaharan Africa. Fam Process Develop 2004; 155-93. Available at: http://www.un.org/esa/socdev/family/Publications/mt bigombe. pdf

[27] Blum RW. Youth in sub-Saharan Africa. J Adolescent Health 2007; 41: 230-8.

[28] Brown S. Family structure and child well-being: the significance of parental cohabitation. J Marriage Fam 2004; 66: 351-67.

[29] Foster G, Williamson J. A review of current literature on the impact of HIV/AIDS on children in sub-Saharan Africa. AIDS 2000; 14: S275-84

[30] Kamali A, Seeley JA, Nunn AJ, Kengeya-Kayondo JF, Ruberantwari A, Mulder DW. The orphan problem: experience of a sub-Saharan Africa rural population in the AIDS epidemic. AIDS Care 1996; 8: 509-15.

[31] Manning WD, Brown SL. Children's economic well-being in married and cohabiting parent families. J Marriage Fam 2006; 68: $345-62$

[32] Dunifon R, Kowaleski-Jones L. Who's in the house? race differences in cohabitation, single-parenthood and child development. Child Develop 2002; 73: 1249-64.

[33] Shucksmith J, Glendinning A, Hendry L. Adolescent drinking behaviour and the role of family life: a Scottish perspective. J Adolescence 1997; 20(1): 85-101

[34] Glendinning A, Schucksmith J, Hendry L. Social class and adolescent smoking behavior. Soc Sci Med 1994; 38(10): 1449-60.

[35] Fergus S, Zimmeran M. Adolescent resilience: a framework for understanding healthy development in the face of risk. Annu Rev Publ Health 2005; 26: 399-419.

[36] O'Donnell L, Stueve A, Duran R, et al. Parenting practices, parents' underestimation of daughters' risks, and alcohol and 
sexual behaviors of urban girls. J Adolescent Health 2008; 42(5): 496- 502.

[37] Rask K, Åstedt-Kurki P, Laippala P. Adolescent subjective wellbeing and realized values. J Adv Nurs 2002; 38: 254-63.

[38] Flewelling RL, Bauman KE. Family structure as a predictor of initial substance use and sexual intercourse in early adolescence. $\mathrm{J}$ Marriage Fam 1990; 52: 171-81.

[39] Patterson J. Integrating family resilience and family stress theory. J Marriage Fam 2002; 64(2): 349-60.

[40] Griffin KW, Botvin GJ, Scheier LM, Diaz T, Miller NL. Parenting practices as predictors of substance use, delinquency, and aggression among urban minority youth: Moderating effects of family structure and gender. Psychol Addict Behav 2000; 14(2): 174-84.

[41] Benzies K, Mychasiuk R. Fostering family resilience: a review of key protective factors. Child Fam Soc Work 2008; 14: 103-14.

[42] Haase A, Steptoe A, Sallis JF, Wardle J. Leisure time physical activity in university students from 23 countries: associations with health beliefs, risk awareness, and national economic development. Prev Med 2004; 39: 182-90.

[43] Patterson JM. Understanding family resilience. J Clin Psychol 2002; 58: 233-46.

[44] Wusu O, Isigo-Abanihe U. Interconnections among changing family structure, childrearing and fertility behaviour among the $O g u$, Southwestern Nigeria: A qualitative study. Demogr Res 2006; 14: 139-56. Available at: http://www.demographic-research.org/V olumes/Vo 114/8

[45] Ojua T, Lukpata F, Atam C. Exploring the neglect of the African family value systems and its effects on sustainable development. Am J Hum Ecol 2014; 3(3): 43-50.

[46] Steptoe A, Wardle J. Health-related behavior: prevalence and links with disease. In: Kaptein A, Weinmen J, Eds. Health Psychology. Oxford: Blackwell 2004.

[47] Louw QA, Morris LD. The prevalence of low back pain in Africa: a systematic review. BMC Musculoskel Dis 2007; 8: 105.

[48] Wong WC, Cheung CS, Hart GJ. Development of a quality assessment tool for systematic reviews of observational studies (QATSO) of HIV prevalence in men having sex with men and associated risk behaviours. Emerg Themes Epidemiol 2008; 5: 23.

[49] Roman N, Frantz J. The prevalence of intimate partner violence in the family: A systematic review of the implications for adolescents in Africa. Fam Pract 2013; 30(3): 256-65.
[50] Negeri EL. Assessment of risky sexual behaviors and risk perception among youths in western Ethiopia: the influences of family and peers: a comparative cross-sectional study. BMC Public Health 2014; 301(14): 1471-2458.

[51] Pilgrim NA, Ahmed S, Gray RH, et al. Sexual coercion among adolescent women in rakai, uganda: does family structure matter? J Interpers Violence 2013; 28(6): 1289-313.

[52] Marchand E, Smolkowski K. Forced intercourse, individual and family context, and risky sexual behavior among adolescent girls. J Adolescent Health 2013; 52: 89-95.

[53] Sidze EM, Defo BK. Effects of parenting practices on sexual risktaking among young people in cameroon. BMC Public Health 2013; 616(13): 1471-2458

[54] Ismayilova L, Ssewamala FM, Karimli L. Family support as a mediator of change in sexual risk-taking attitudes among orphaned adolescents in rural Uganda. J Adolescent Health 2012; 50: 228-35.

[55] Defo BK, Dimbuene ZT. Influences of family structure dynamics on sexual debut in Africa: implications for research, practice and policies in reproductive health and social development. Afr J Reprod Health 2012; 16 (2) 147-72.

[56] Ntaganira J, Hass LJ, Hosner S, Brown L, Mock NB. Sexual risk behaviors among youth heads of household in Gikongoro, South Province of Rwanda. BMC Public Health 2012; 12: 1-13.

[57] Dimbuene ZT, Defo BK. Fostering accurate HIV/AIDS knowledge among unmarried youths in Cameroon: do family environment and peers matter? BMC Public Health 2011; 11: 2-12.

[58] Camlin CS, Snow RC. Parental investment, club membership, and youth sexual risk behavior in Cape Town. Natl Inst Health 2008; 35(4): 522-40.

[59] Adu-Mireku S. Family communication about HIV/AIDS and sexual behaviour among senior secondary school students in Accra, Ghana. Afr Health Sci 2003; 3(1): 7-14.

[60] Magnani RJ, Karim AM, Weiss LA, Bond KC, Lemba M, Morgan G. Reproductive health risk and protective factors among youth in Lusaka, Zambia. J Adolescent Health 2002; 30, 76-86.

[61] Shisana, O, Rehle, T, Simbayi LC, et al. South African national HIV prevalence, incidence and behaviour survey. Cape Town: HSRC Press 2012.

[62] Mishra V, Bignami-Van Assche S. Orphans and vulnerable children in high HIV- prevalence countries in Sub-Saharan Africa. DHS Analytical Studies No. 15. Calverton, Maryland, USA: Macro International Inc 2008

(C) Frantz et al.; Licensee Bentham Open.

This is an open access article licensed under the terms of the Creative Commons Attribution Non-Commercial License (http://creativecommons.org/licenses/by-nc/3.0/) which permits unrestricted, non-commercial use, distribution and reproduction in any medium, provided the work is properly cited. 